\title{
Symmetry of single-phase loads in four-wire three- phase networks of alternating sinusoidal current
}

\author{
Kizurov Anatoly Sergeevich \\ Mechanics and Technology Institute \\ FSBEI HE Northern Trans-Ural SAU \\ Tyumen, Russia \\ Impossible_@mail.ru
}

\begin{abstract}
To reduce losses in the zero conductor of threephase alternating current networks, it is proposed to use a switching device made on the basis of semiconductor thyristors, in order to enable the single-phase consumer to be connected to the required phase of power supply in order to reduce asymmetry. An algorithm for the operation of this device is developed and presented. Modeling of various schemes of connection of single-phase consumers allowed to make a conclusion about the expediency of the proposed measures.
\end{abstract}

Keywords- Asymmetry; single-phase consumers; redistribution

\section{INTRODUCTION}

To reduce the negative consequences created by unbalanced loads (including several single-phase consumers, which entails an increase in the electrical potential at the zero working bus, deviation of the electric voltage of the electric receiver, phase misalignment), it is necessary to use a technological device that includes microcontroller equipment with a measuring complex and providing measurement of load currents of single-phase consumers, redistribution of supply phases and provision of protection against emergency modes [1].

A distinctive feature is the redistribution of loads of singlephase consumers to a three-phase network, characterized by a switching time of not more than one half-cycle for networks with a frequency of $50 \mathrm{~Hz}$ (up to $10 \mathrm{~ms}$ ).

The existing analogs of asymmetry reduction devices operate by the principle of electromagnetic transformations and have a number of serious shortcomings that are absent in the proposed solution [2, 3].

At the stage of developing the principles and algorithms of the asymmetry reduction device, theoretical and experimental studies were performed, the results of which are presented in this article.

\section{THEORETICAL BACKGROUND}

The experience of repair work in electrical installations with single-phase consumers (including in household electrical systems), it was noted that the most common is burning with the destruction of the zero working conductor in junction boxes and electric boards. The effect of the destruction of the zero conductor due to excessive heating is due to the presence of a potential other than $0 \mathrm{~V}$ on the bus as a result of the non-symmetry of the load.

An example of an asymmetric electrical circuit of substitution and its vector diagram are shown in Figures 1 and 2.

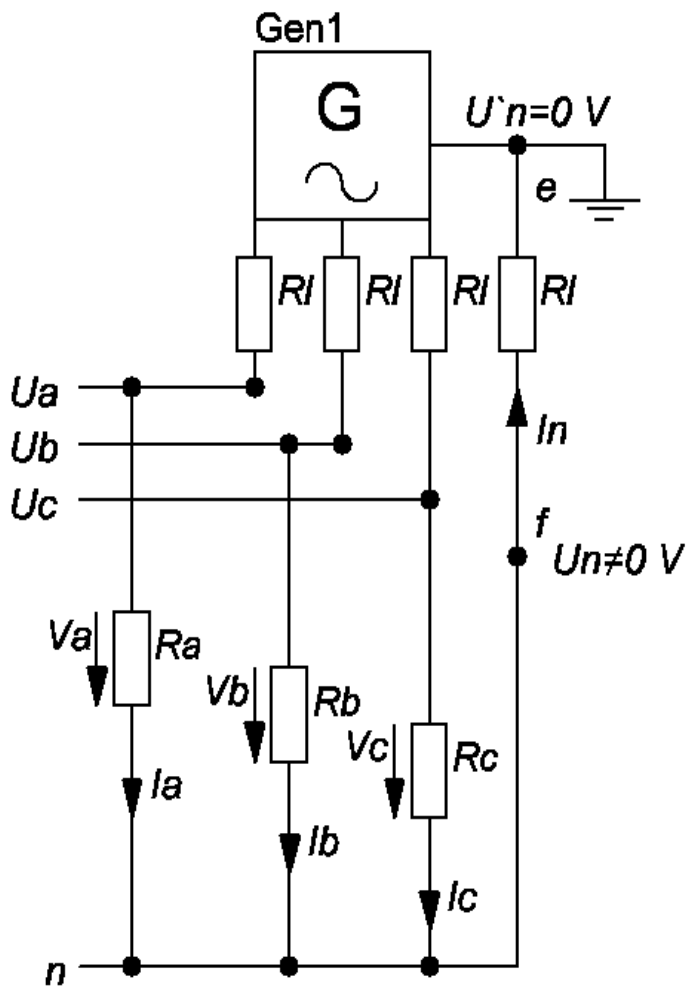

Fig. 1. The electrical scheme for replacing the asymmetric load of singlephase consumers in a three-phase four-wire network of alternating sinusoidal current.

Similarly, schemes of electricity supply for single-phase consumers of household distribution networks are presented [4]. 
The current strength and the voltage between nodes (e) and (f) (Fig. 1) characterize the loss power in the zero working wire (1):

$$
\mathrm{S}=\mathrm{In} \cdot \mathrm{Vn}, \mathrm{VA},
$$

where In - the complex of the current flowing through the zero working conductor, $\mathrm{A}$;

$\mathrm{Vn}$ - the stress complex between nodes (e) and (f), V

Voltage complex Vn between nodes (e) and (f) is determined from the expression for the nodal potentials (2):

\section{$V n=\left(U a \cdot G^{`} a+U b \cdot G^{`} b+U c \cdot G^{`} c\right) /\left(G^{`} a+G^{`} b+G^{`} c+G n\right), V$}

where $\mathrm{Ua}, \mathrm{Ub}, \mathrm{Uc}$ - the complex of phase voltages of phases A, B and C of the electric power source, respectively, $\mathrm{V}$;

$\mathrm{G} i \mathrm{i}=1 /(\mathrm{Ri}+\mathrm{Rl})-$ the complex of electrical conductors taking into account the resistance of conductors, $\mathrm{S}$;

$\mathrm{Gn}=1 / \mathrm{Rl}-$ conductivity of the zero working conductor, $\mathrm{S}$.

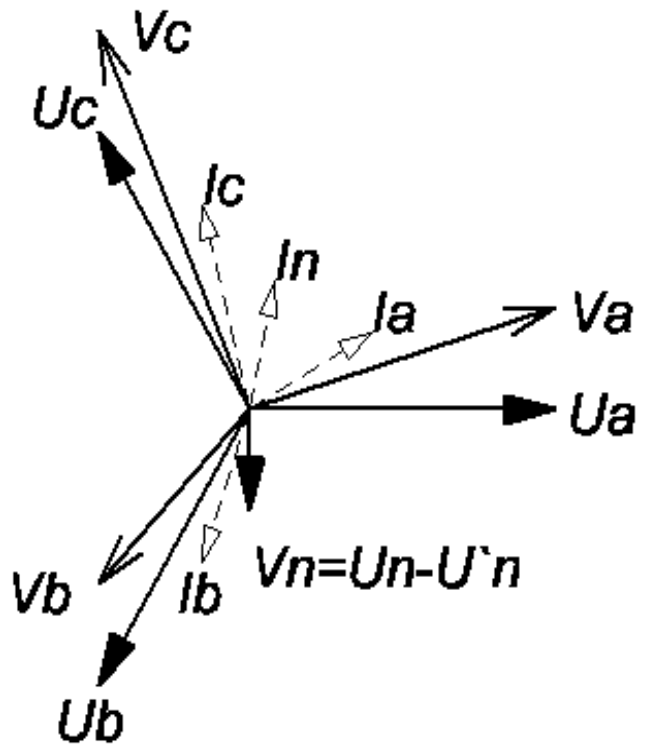

Fig. 2. An example of a combined vector diagram of currents and voltages applied to Fig. 1.

Value $\mathrm{Vn}=0 \mathrm{~V}$ is obtained if the phase conductivities are equal to each other $G^{`} a=G^{`} b=G^{`} c$. The equality of the phase conductivities is a condition for the symmetry of the loads.

When designing switchboards, they try to alternate the outgoing groups in accordance with the load capacity so that the load capacities of the phases are equal to each other. An example of a symmetrical distribution of loads is shown in Fig. 3.

When at least one consumer is disconnected, the circuit ceases to satisfy the condition of a symmetrical circuit and an electric current arises in the zero conductor.

\section{SIMULATION OF THE EXPERIMENTAL SCHEME}

Equations 1 and 2 and the data in Fig. 3, various variants of the operation of the circuit were modeled. In the simulation, the following assumptions were made: the power factors of each electric receiver is $\cos =0.9$; rated phase voltage is $\mathrm{U}=$ $220 \mathrm{~V}$; resistance of one current-carrying core is $\mathrm{R}=0,1 \Omega$. Table I shows the connection options with maximum asymmetry.

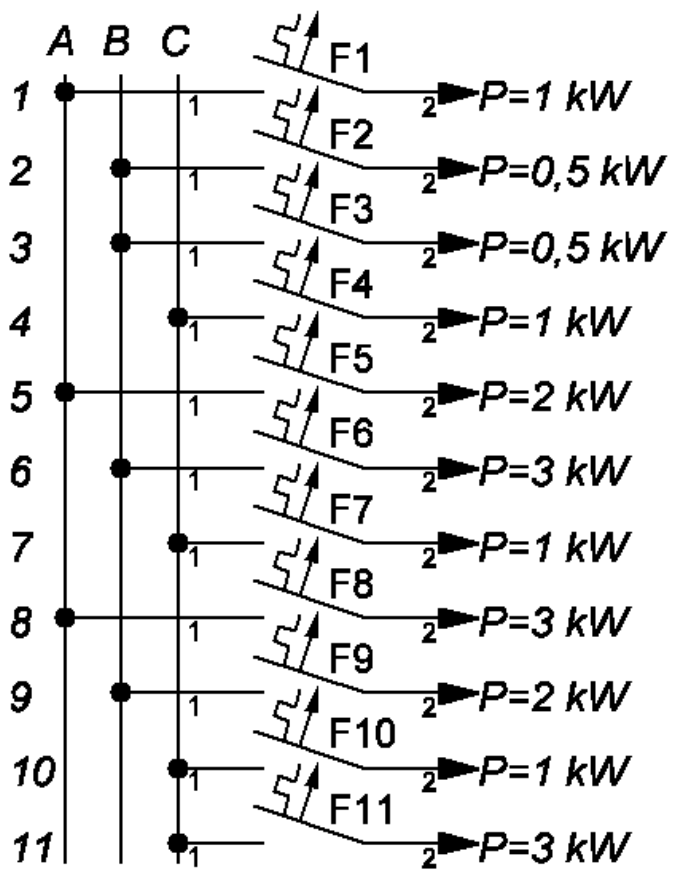

Fig. 3. A diagram of a switchboard with a symmetrical load.

TABLE I. SIMULATION OF THE ASYMMETRY OF THE SCHEME IN FIG. 3

\begin{tabular}{|c|c|c|c|c|c|c|c|c|c|c|}
\hline \multirow{2}{*}{$\begin{array}{c}\text { Customer } \\
\text { number }\end{array}$} & \multicolumn{10}{|c|}{ Schematic № } \\
\hline & 0 & 1 & 2 & 3 & 4 & 5 & 6 & 7 & 8 & avg \\
\hline 1 & A & A & A & A & & A & & A & A & \\
\hline 2 & B & & B & & & B & B & B & & \\
\hline 3 & B & $\mathrm{B}$ & B & B & B & B & B & B & & \\
\hline 4 & $\mathrm{C}$ & & & & $\mathrm{C}$ & & $\mathrm{C}$ & $\mathrm{C}$ & & \\
\hline 5 & A & A & A & A & A & A & A & & A & \\
\hline 6 & B & & B & & & & & B & B & \\
\hline 7 & $\mathrm{C}$ & $\mathrm{C}$ & & $\mathrm{C}$ & $\mathrm{C}$ & & $\mathrm{C}$ & $\mathrm{C}$ & & \\
\hline
\end{tabular}




\begin{tabular}{|l|c|c|c|c|c|c|c|c|c|c|}
\hline \multirow{2}{*}{$\begin{array}{c}\text { Customer } \\
\text { number }\end{array}$} & \multicolumn{10}{|c|}{ Schematic № } \\
\hline & $\mathbf{0}$ & $\mathbf{1}$ & $\mathbf{2}$ & $\mathbf{3}$ & $\mathbf{4}$ & $\mathbf{5}$ & $\mathbf{6}$ & $\mathbf{7}$ & $\mathbf{8}$ & $\boldsymbol{a v g}$ \\
\hline 8 & A & A & A & A & A & A & A & & A & \\
\hline 9 & B & & B & & & & & B & & \\
\hline 10 & C & & C & C & C & C & C & C & C & \\
\hline 11 & C & & & & C & C & C & C & & \\
\hline $\mathrm{Pa}, \mathrm{kW}$ & 6 & 6 & 6 & 6 & 5 & 6 & 5 & 1 & 6 & \\
\hline $\mathrm{Pb}, \mathrm{kW}$ & 6 & 0,5 & 6 & 0,5 & 0,5 & 1 & 1 & 6 & 3 & \\
\hline $\mathrm{Pc}, \mathrm{kW}$ & 6 & 1 & 1 & 2 & 6 & 4 & 6 & 6 & 1 & \\
\hline $\mathrm{Vn}, \mathrm{V}$ & 0 & 2,8 & 2,7 & 2,6 & 2,5 & 2,4 & 2,3 & 2,2 & 2,1 & 1,34 \\
\hline $\mathrm{Pn}, \mathrm{W}$ & 0 & 79 & 75 & 70 & 67 & 59 & 57 & 50 & 49 & 18,0 \\
\hline
\end{tabular}

When modeling the various options for switching off single-phase consumers, the voltage on the zero working wire was detected as a result of asymmetry. If there is an asymmetry along the zero working wire, an electric current starts flowing, which characterizes the power of losses in the form of heat. On average, among all possible options, the power loss in the zero working wire (under the condition of resistance $0.1 \Omega$, which corresponds to a wire length of $10 \mathrm{~m}$ ) was $18 \mathrm{~W}$.

In the cases, presented in Table 1 , to reduce the asymmetry, it is necessary to redistribute the supply phases. For redistribution of phases, an algorithm of calculation was developed (hereinafter the Algorithm).

The algorithm envisaged a search of various variants of connection of consumers (further Brute) with memorization of variants with minimal asymmetry. The block diagram of the algorithm is shown in Figure 4.

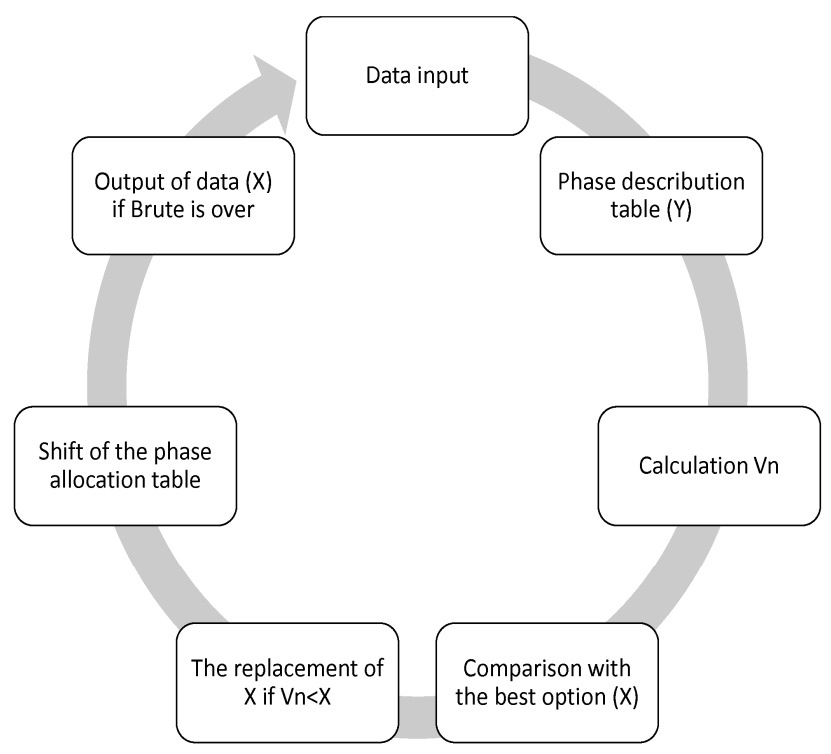

Fig. 4. A block diagram of the Algorithm for the redistribution of supply phases.

For the data in Table I, the results of the Algorithm (Figure 4) are shown in Table II.
TABLE II. MODELING OF REDISTRIBUTION OF CONNECTION OF CONSUMERS

\begin{tabular}{|c|c|c|c|c|c|c|c|c|c|c|}
\hline \multirow{2}{*}{$\begin{array}{c}\text { Customer } \\
\text { number }\end{array}$} & \multicolumn{10}{|c|}{ Schematic № } \\
\hline & 0 & 1 & 2 & 3 & 4 & 5 & 6 & 7 & 8 & avg \\
\hline 1 & $\mathrm{C}$ & B & $\mathrm{C}$ & $\mathrm{C}$ & & B & & $\mathrm{C}$ & A & \\
\hline 2 & $\mathrm{C}$ & & B & & & $\mathrm{C}$ & $\mathrm{C}$ & B & & \\
\hline 3 & $\mathrm{C}$ & B & A & A & $\mathrm{B}$ & A & $\mathrm{C}$ & A & & \\
\hline 4 & $\mathrm{C}$ & & & & $\mathrm{C}$ & & $\mathrm{C}$ & B & & \\
\hline 5 & $\mathrm{C}$ & $\mathrm{C}$ & B & $\mathrm{C}$ & $\mathrm{C}$ & B & $\mathrm{C}$ & & A & \\
\hline 6 & B & & $\mathrm{C}$ & & & & & $\mathrm{C}$ & $\mathrm{C}$ & \\
\hline 7 & $\mathrm{C}$ & B & & A & $\mathrm{C}$ & & B & B & & \\
\hline 8 & B & A & A & B & $\mathrm{B}$ & $\mathrm{C}$ & B & & B & \\
\hline 9 & A & & B & & & & & B & & \\
\hline 10 & A & & A & A & A & B & A & A & A & \\
\hline 11 & A & & & & A & A & A & A & & \\
\hline $\mathrm{Pa}, \mathrm{kW}$ & 6 & 3 & 4,5 & 2,5 & 4 & 3,5 & 4 & 4,5 & 4 & \\
\hline $\mathrm{Pb}, \mathrm{kW}$ & 6 & 2,5 & 4,5 & 3 & 3,5 & 4 & 4 & 4,5 & 3 & \\
\hline $\mathrm{Pc}, \mathrm{kW}$ & 6 & 2 & 4 & 3 & 4 & 3,5 & 4 & 4 & 3 & \\
\hline Vn, V & 0 & 0,4 & 0,6 & 0,7 & 0,3 & 0,4 & 0,3 & 0,4 & 0,65 & 0,44 \\
\hline Pn, W & 0 & 2 & 3,7 & 4,5 & 0,7 & 1,8 & 0,7 & 1,6 & 4,2 & 1,9 \\
\hline
\end{tabular}

To analyze the efficiency of the algorithm, a program was written in the Arduino IDE (Sketch) development environment and tested on an ATmega328 microcontroller with a clock frequency of $18 \mathrm{MHz}[5,6,7]$.

\section{OPEN SOURCE PROGRAM CODE}

The Sketch source code provides an estimate of the time of finding the optimal connection option and the calculation of the Brute time. The source code for Sketch is shown below.

Const int $\mathrm{n}=7$; // number of single-phase consumers

Float $\mathrm{p}[\mathrm{n}]$; // capacity array of active

Float c [n]; // an array of capacities of reactive

Int $\mathrm{f}[\mathrm{n}]$; // array of current phases of consumer nutrition

Int ff [n]; // array of the most even connection to phases

Boolean $\mathrm{z}=0$; // 0- Brute is not finished

Float $s[2]=\{0,0\} ; / /$ total capacity active all consumers

Float a [2]; // total load power in phase A

Float $\mathrm{b}[2]=\{0,0\}$; // total load power in phase $\mathrm{B}$

Float cc $[2]=\{0,0\} ; / /$ total load power in phase $\mathrm{C}$

Boolean $\mathrm{q}=0 ; / / 0$-results Brute is not inferred

Float $\mathrm{mm}$ [2] $=\{100000,100000\} ; / /$ maximum asymmetry, $\mathrm{W}$

Unsigned long t; // start / end time Brute, ms 

ms

Unsigned long tt; // optimum connection time for phases,

Void setup () $\{\mathrm{A}[0]=0.00 ; \mathrm{A}[1]=0.00$;

Serial.begin (250000); // configure the serial port for a speed of 250000

$\mathrm{P}[0]=2200.00 ; \mathrm{P}[1]=600.00 ; \mathrm{P}[2]=7.00 ; \mathrm{P}[3]=5.00 ;$ $\mathrm{P}[4]=3000.00 ; \mathrm{P}[5]=1800.00 ; \mathrm{P}[6]=550.00$;

$\mathrm{C}[0]=0.00 ; \mathrm{C}[1]=197.21 ; \mathrm{C}[2]=2.30 ; \mathrm{C}[3]=1.64 ; \mathrm{C}$ $[4]=2406.84 ; \mathrm{C}[5]=0.00 ; \mathrm{C}[6]=180.78$; array

For (int $\mathrm{i}=0 ; \mathrm{i}<\mathrm{n} ; \mathrm{i}=\mathrm{i}+1$ ) // cycle of filling the capacity OPs

$\{\mathrm{S}[0]=\mathrm{s}[0]+\mathrm{p}[\mathrm{i}] ; / /$ calculation of the total power of all

$\mathrm{S}[1]=\mathrm{s}[1]+\mathrm{c}[\mathrm{i}] ; \mathrm{F}[\mathrm{i}]=1 ; / /$ assign a connection with the serial number i to phase A (1)

\} $\mathrm{T}=$ millis ()$; / /$ start time Brute $\}$

Void loop () \{// Brute

If $(\mathrm{z}==0) / /$ if the selection is not completed, then this block is executed

$\{\mathrm{A}[0]=0 ; \mathrm{B}[0]=0 ; \mathrm{Cc}[0]=0 ; \mathrm{A}[1]=0 ; \mathrm{B}[1]=0 ; \mathrm{Cc}$ $[1]=0 ; / /$ zeroing of the value of load powers by phases

For (int $\mathrm{i}=0 ; \mathrm{i}<\mathrm{n} ; \mathrm{i}=\mathrm{i}+1)\{$

If (f [i] == 1) $\{\mathrm{a}[0]=\mathrm{a}[0]+\mathrm{p}[\mathrm{i}] ; \mathrm{A}[1]=\mathrm{a}[1]+\mathrm{c}[\mathrm{i}] ;\} / /$ calculate the total load for phase A (1) with the current connection variant

If (f [i] $==2)\{\mathrm{b}[0]=\mathrm{b}[0]+\mathrm{p}[\mathrm{i}] ; \mathrm{B}[1]=\mathrm{b}[1]+\mathrm{c}[\mathrm{i}] ;\} / /$ - // - B (2) - // -

If $(\mathrm{f}[\mathrm{i}]==3)\{\mathrm{cc}[0]=\mathrm{cc}[0]+\mathrm{p}[\mathrm{i}] ; \mathrm{Cc}[1]=\mathrm{cc}[1]+\mathrm{c}$ [i];\} // - // - C (3) - // -

// Serial.println (c [i]);

\}Float $\mathrm{xab}=\mathrm{abs}(\mathrm{a}[0]-\mathrm{b}[0])$; // the load deviation to phase A (1)

Float $x b c=$ abs (b [0] -cc [0]); // -//- AT 2) -//-

Float xac = abs (cc [0] -a [0]);// - // - C (3) - // -

Float $a b c=\max (x a b, x b c)$; // Determine the maximum load deviation by phase with the current connection variant

Float $\mathrm{m}=\max (\mathrm{abc}, \mathrm{xac}) ; / /$ - // A (1)

Float $\mathrm{xabq}=\mathrm{abs}(\mathrm{a}[1]-\mathrm{b}[1])$; // load deflection OP phase

Float $x b c q=$ abs $(b[1]-c c[1]) ; / /-/ /-$ AT 2) -//-

Float xacq = abs (cc [1] -a [1]); // - // - C (3) - // -

Float abcq $=\max (\mathrm{xabq}, \mathrm{xbcq}) ; / /$ Determine the maximum load deviation by phase with the current connection variant

Float $\mathrm{mq}=\max ($ abcq, xacq $)$;

Serial.print (m); Serial.print ("\t"); Serial.print (mq);

$$
\mathrm{M}=\operatorname{sqrt}(\mathrm{sq}(\mathrm{m})+\mathrm{sq}(\mathrm{mq}))
$$

Serial.print ("\t"); Serial.println (m);

If $(\mathrm{m}<\mathrm{mm}[0]) / / \& \& \mathrm{mq}<\mathrm{mm}[1]) / /$ if the current connection variant has a deviation below the saved one

$\{\mathrm{Tt}=$ millis ()$-\mathrm{t}$; // time definition of the optimal connection option

For (int $\mathrm{i}=0$; i $<\mathrm{n} ; \mathrm{i}=\mathrm{i}+1$ ) $\{\mathrm{ff}[\mathrm{i}]=\mathrm{f}[\mathrm{i}] ;\} / /$ keep the optimal connection at a given time

$\mathrm{Mm}[0]=\mathrm{m}$; // preservation of the maximum deviation of loads by phases with the current optimal version

\} $\mathrm{F}[0]=\mathrm{f}[0]+1 ; / /$ connect the consumer with the number 0 to the next phase

For (int $\mathrm{i}=0 ; \mathrm{i}<\mathrm{n}-1 ; \mathrm{i}=\mathrm{i}+1$ ) // assignment of the numbers of the phases of connection of consumers

$\{$ If $(\mathrm{f}[\mathrm{i}]==4)\{\mathrm{f}[\mathrm{i}+1]=\mathrm{f}[\mathrm{i}+1]+1 ; \mathrm{F}[\mathrm{i}]=1 ;\}$

\}If (f [n-1] == 2) // stop Brute

$\{\mathrm{F}[\mathrm{n}-1]=1$;

$\mathrm{Z}=1 ; / /$ Brute is over

$\mathrm{T}=$ millis ()$-\mathrm{t} ; / /$ end time Brute

\}\}// the cycle of the output of the selection of the optimal connection

If $(\mathrm{z}==1 \& \& \mathrm{q}==0) / /$ if Brute is finished and no results were output

$\{\mathrm{A}[0]=0 ; \mathrm{B}[0]=0 ; \mathrm{Cc}[0]=0 ; \mathrm{A}[1]=0 ; \mathrm{B}[1]=0 ; \mathrm{Cc}$ $[1]=0$; // zeroing the load capacities by phases

For (int $\mathrm{i}=0 ; \mathrm{i}<\mathrm{n} ; \mathrm{i}=\mathrm{i}+1$ )

$\{$ Int $x=p$ [i]; Serial.print (x); Serial.print ("\t"); If (ff [i] $==1)\{\mathrm{a}[0]=\mathrm{a}[0]+\mathrm{x}$; $\}$ if $(\mathrm{ff}[\mathrm{i}]==2)\{\mathrm{b}[0]=\mathrm{b}[0]+\mathrm{x} ;\}$ if Ff $[i]==3)\{\mathrm{cc}[0]=\mathrm{cc}[0]+\mathrm{x} ;\}\} / /$ output the power of the users from the array and calculate the loads in phases, $\mathrm{W}$

Serial.println (); //line break

For (int $\mathrm{i}=0 ; \mathrm{i}<\mathrm{n} ; \mathrm{i}=\mathrm{i}+1$ )

\{If (ff $[\mathrm{i}]==1$ ) $\{$ Serial.print $(" \mathrm{~A} ")$; $\}$ if (ff $[\mathrm{i}]==2$ ) \{Serial.print ("B"); $\}$ if (ff $[\mathrm{i}]==3$ ) \{Serial.print ("C"); Serial.print ("\t"); $\}$ // output the numbers of the phases of connection of consumers

Serial.println (); //line break

For (int $\mathrm{i}=0 ; \mathrm{i}<\mathrm{n} ; \mathrm{i}=\mathrm{i}+1$ )

\{Serial.print ("..."); Serial.print ("\t");\} // delimiter

Serial.println (); //line break

$\mathrm{Q}=1 ; / /$ the data is output

Serial.print ("Times ="); Serial.print (tt); Serial.print ("/"); Serial.println (t); // Display the Brute time / before determining the optimal value, $\mathrm{ms}$

\} \}End Sketch. 


\section{RESULTS OF THE EXPERIMENT}

An analysis of Sketch's work showed the non-linear nature of the change in Brute time for a different number of consumers. The graphical dependence of Brute time on the number of consumers is shown in Figure 5.

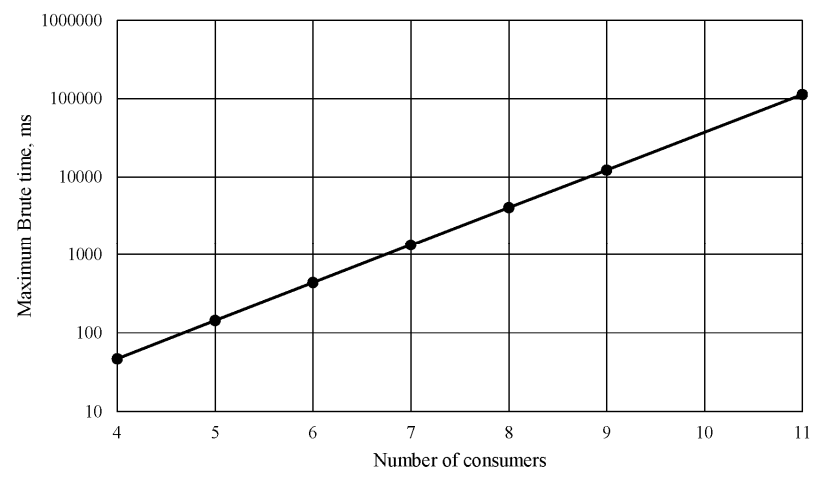

Fig. 5. Graphic dependence of the maximum time of the Brute algorithm, depending on the number of consumers.

As can be seen in Figure 5, the time of Brute with the number of consumers, exceeding 6 , exceeds $\mathrm{T}>1 \mathrm{~s}$, therefore, with more consumers, it is necessary to group them to speed up Brute.

To implement the algorithm in a technical device for switching, it is necessary to use semiconductor elements, such as optocouplers and thyristors [8,9].

The technical device is a printed circuit board with a set of thyristors and optocouplers as well as measuring modules for each consumer. To connect, each consumer provides one section. Each section contains 6 thyristors and 6 optocouplers, as well as one voltage divider.

Voltage dividers provide a signal to the analog input of the microcontroller in which the instantaneous potential of the outgoing group is measured.

Three voltage dividers are installed in the incoming phases of the technical device. The signal from the voltage dividers of the incoming phases is also fed to the analog inputs of the microcontroller. When comparing the values of analog signals from the supply phases and outgoing groups, the microcontroller determines the value of the current consumed and the phase angle.

The value of the current strength is determined by the voltage drop across the thyristor in accordance with its current-voltage characteristic.

A digital signal from the microcontroller is fed to the optocoupler LED, which controls the operation of the thyristors. In each section, only one thyristor can be connected at a time, which allows switching within one period.

An electrical schematic diagram of one section of a technical device is shown in Figure 6.

Since the technical device is a set of sections, it is necessary to determine the quantity of analog and digital ports to select a microcontroller.

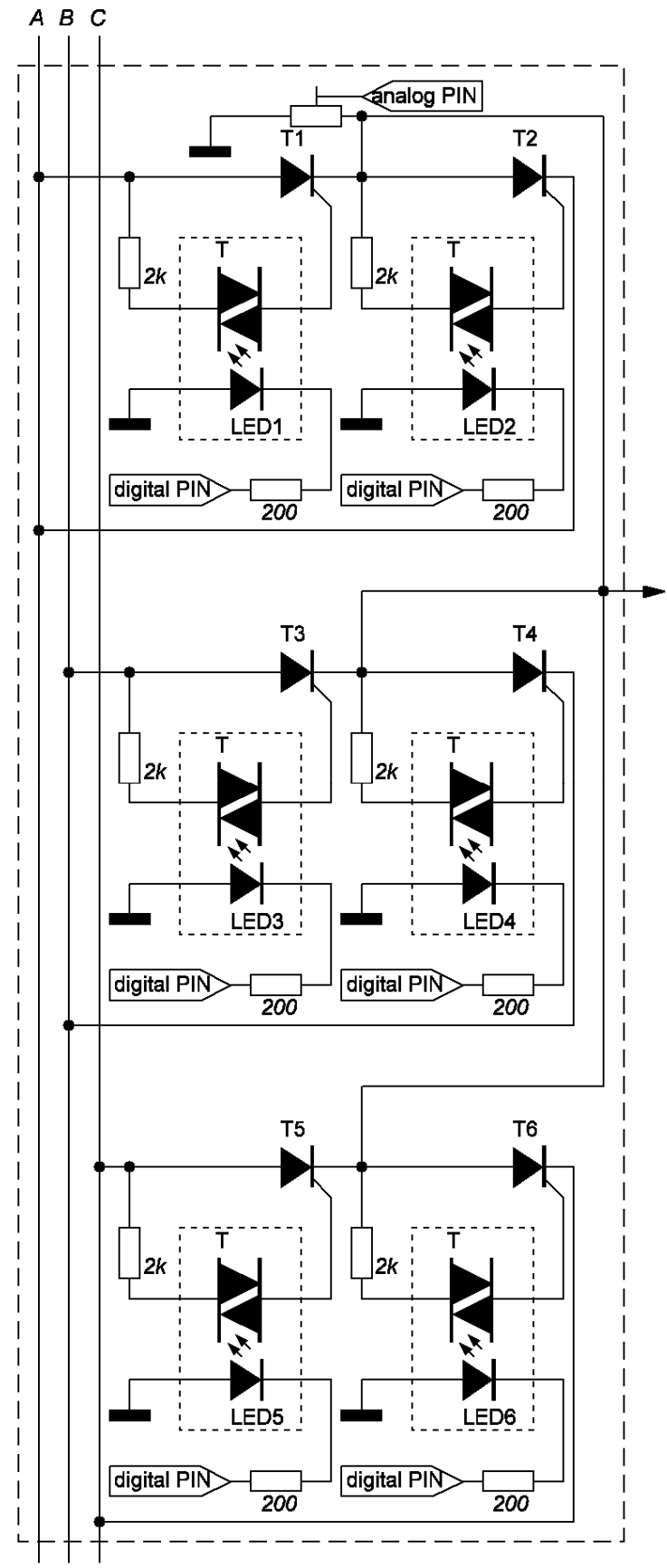

Fig. 6. The basic electrical diagram of one section of the technical device.

To determine the quantity of digital ports, one must use the following expression:

$$
\mathrm{Nd}=6 \cdot \mathrm{N}
$$

where $\mathrm{Nd}$ is the quantity of digital ports of the microcontroller;

$\mathrm{N}$ - quantity of outgoing groups (sections). 
To determine the quantity of analog ports, let us use the following expression:

$$
\mathrm{Na}=3+\mathrm{N} .
$$

The principle of the device is to read the instantaneous values of the potential of incoming phases, to read instantaneous values of the potential of the outgoing groups, to calculate the current consumed, to perform the Brute and switch. The algorithm of the technical device is shown in Figure 7.

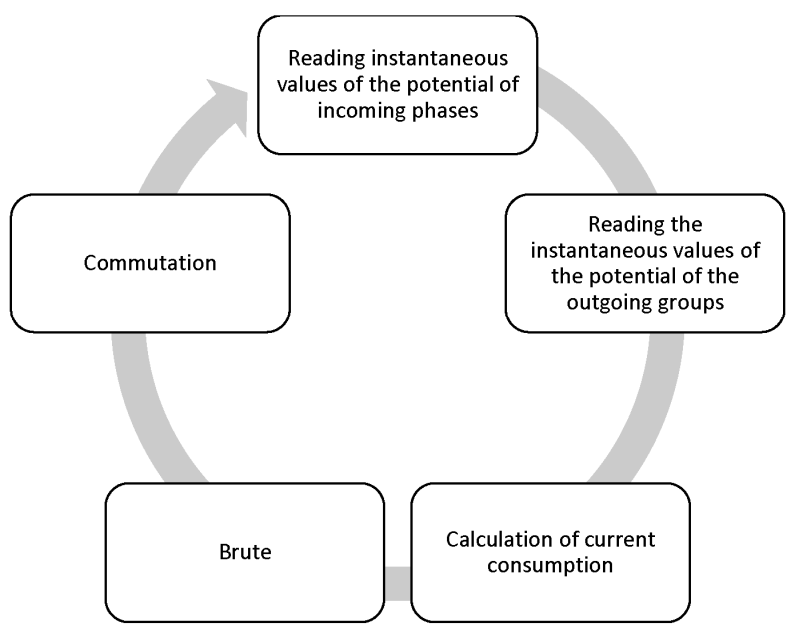

Fig. 7. The algorithm of the technical device.

The commutation is performed in the following order: all thyristors are turned off; if the potential of the ascending group is zero, then the thyristor pair is switched on.

Since the devices have the ability to measure the consumer's voltage and current, it becomes possible to measure active power, full power and power factor. The use of a microcontroller to control thyristor pairs allows the remote switching on and off for consumers, as well as protection from emergency operation modes.

The finished technical device can be manufactured in a casing with the appropriate mounting on the din-rail. This will make it possible to replace switching devices and protection devices in existing electrical installations with the proposed technical device without changing the design features. The proposed technical device will simplify the assembly of electrical distribution boards.

\section{CONCLUSION}

At present, a laboratory sample of a device for reducing the asymmetry of single-phase loads has been assembled and its test is being carried out for the reliability of operation and the possibility of performing protective functions.
As mentioned earlier, increasing the number of outgoing groups leads to an increase in the Brute time. So to speed up the selection process, one should break the number of outgoing groups into several subgroups and perform the Brute Algorithm inside each subgroup. Using a microcontroller allows different interfaces to communicate with other similar devices. Thus, it is possible to build large switching circuits with integrated communication (including remote control and connection to the Internet).

Using a system to reduce the asymmetry of single-phase loads in three-phase four-wire networks together with an improved Algorithm will reduce the asymmetry, which will lead to a reduction in losses on the zero working wire (for the simulated situation) from $18 \mathrm{~W}$ to $1.9 \mathrm{~W}$ or $89 \%[10,11]$.

It is also possible to add measurement functions to the body of Sketch to provide protection from consumers' work in emergency modes and metering of electricity, to include remote switching and to integrate the device into the «Smart Home» or «Automated House system».

\section{References}

1] J. Driesen, V. T. Craenenbroeck. "Introduction to asymmetry"/Dr Johan Driesen \& Dr Thierry Van Craenenbroeck, Katholieke Universiteit Leuven; Per. With the English. E. V. Melnikova // Energy saving: the journal, vol.6, March 2004.

[2] Bruce A. Eggers. "An Analysis of the Balun”,QST, pp. 19-21, April, 1980.

[3] V.S. Klimash, D.P. Svetlakov. "Analysis of the physical processes of the compensator of reactive power with the symmetry of the network current and a new control principle", ELECTRO. Electrical engineering, electric power industry, electrotechnical industry, Holding company "Electrozavod" (Moscow), Russia, vol.5, pp. 18-22, 2007.

[4] A.A, Khudyakov, M.L. Sapunkov. "Investigation of the effect of phase conductivity asymmetry on the ground on the functioning of protection against single-phase faults", research and innovation, Russia, vol.2, pp. 79-85, 2010.

[5] V.A. Petin. "Projects using the Arduino controller", BHV-Petersburg, P.400, 2014. - ISBN 9785977533379.

[6] Glassner, Andrew, "Processing for Visual Artists: How to Create Expressive Images and Interactive Art" (1st ed.), A K Peters/CRC Press, pp. 955, August 2010. - ISBN 1-56881-716-9.

[7] Reas, Casey \& Fry, Ben. "Getting Started with Processing" (1st ed.), Make, P. 208, June 2010 - ISBN 1-4493-7980-X.

[8] Ya.S. Kublanovsky. "Thyristor devices. - 2 nd ed., Pererab. And additional". Radio and Communication, Moscow, Russia, vol.1104, P.112, 1987.

[9] A.K. GrebnevK, V.N. Gridin, V.P. Dmitriev. "Optoelectronic elements and devices" / Under. Ed. Yu. V. Gulyaeva. Radio and Communication, Moscow, Russia, P.336, 1998. - ISBN 5-256-01385-8.

[10] J. Palecek, V. Kolar, V. Styskala, Y.I. Jarkov. "Influence of AC electric railways on power supply system - voltage asymmetry", bulletin of the Rostov state university of transportation messages, Russia, vol.2(42), pp.149-154, 2011.

[11] A.N. Plahotniuc, Yu.A. Angelica. "Generalized criterion for the assessment and quality control of electric power for impulse load and asymmetry of voltages and currents", electromechanical power converters "EMPC-03". Materials of the second interuniversity scientific conference, March 27-28, 2003, Krasnodar, Russia, pp. 74-77, March 2003. 